\title{
Study on the Deep Learning of Physics Review Course in Junior Middle School Based on CRS
}

\author{
Wei Li, Zhi Xin Huang*, Ming Hai Wu, Qi Tian \\ College of Physical Science and Technology, Central China Normal University, Wuhan, China \\ Email address: \\ 20018307@qq.com (Wei Li), huangzx@mail.ccnu.edu.cn (Zhi Xin Huang),672362566@qq.com (Ming Hai Wu), \\ 879750624@qq.com (Qi Tian) \\ *Corresponding author
}

\section{To cite this article:}

Wei Li, Zhi Xin Huang, Ming Hai Wu, Qi Tian. Study on the Deep Learning of Physics Review Course in Junior Middle School Based on CRS. Science Journal of Education. Vol. 9, No. 3, 2021, pp. 104-109. doi: 10.11648/j.sjedu.20210903.15

Received: April 26, 2021; Accepted: May 19, 2021; Published: May 26, 2021

\begin{abstract}
Deep learning is an important research topic in the field of educational technology, the Horizon Report released by the New Media Alliance in 2017 points out that deep learning is a key direction in promoting educational development and reform. This research is based on the CRS review discussion teaching mode, applying classroom response system in interactive teaching environment, in order to promot students' deep learning. Aiming at the problems of single teaching method, simple classroom communication, fuzzy monitoring of learning situation and low efficiency of teaching goal in junior high school physics review course, this paper takes junior high school physics review course as an example, discusses the teaching efficiency of CRS-based review course qualitatively, and uses comparative experiment to analyze the difference between teaching effect, students' deep learning achievement degree and learning type. The results show that, Based on the CRS junior high school physics review class in-depth learning model can improve students' academic performance, enhance the degree of achievement of students' deep learning. Therefore, we should actively explore the deep integration path of CRS and physics teaching, give full play to the advantages of CRS in focusing on the core issues in the classroom, evaluation of innovative learning process to improve the effectiveness of physics teaching.
\end{abstract}

Keywords: Classroom Response System, Deep Learning, Middle School Physics Review

\section{Introduction}

The theory of deep learning is proposed by American scholars Marton and Saljo [1] on the basis of reading experiments to deal with the shallow learning phenomena of isolated memory and non-critical acceptance of knowledge. Before that, Bloom's classification of cognitive dimensions in his book, Classification of Educational Goals, already contains the idea that learning has deep and shallow levels [2]. Corresponding to shallow learning, deep learning is a kind of learning aimed at promoting the development of students' critical thinking and innovative spirit. It not only emphasizes the integration of knowledge and the connection of meaning, but also emphasizes the improvement of students' advanced thinking and complex problem solving ability [3]. There are some problems such as the simplification of teaching simple classroom communication, fuzzy monitoring of learning situation and low efficiency of teaching goal in physics review course of junior middle school in China [4]. Improving the efficiency of junior high school physics review class and achieving the goal of students' deep learning are the special concerns of educators.

By effectively mobilizing students' active participation and interaction, solving the dilemma of inefficient teaching objectives in face-to-face teaching, realizing problem solving and constructing higher-order thinking, Classroom response system (CRS) has its unique application value. CRS has the function of immediate feedback [5, 6]. A lot of world-class universities, such as Harvard University, Ohio State University and the University of Washington, and a large number of primary and secondary schools have used CRS systems in classrooms [7-8]. Many literature reports that the combination of Clicker classroom teaching has a positive impact on students' enthusiasm for learning, understanding and mastery of knowledge, and students' sense of achievement after constructing new knowledge [9, 10]. The 
further research shows that combining the second generation CRS represented by Clicker with the classroom teaching mode of deep learning and applying it reasonably in the college physics classroom can promote students to think positively about physics problems [11]. Deepen students' understanding of the problem, and then improve students' academic performance $[12,13]$. With the development of artificial intelligence and big data technology, a new generation of CRS is formed by combining CRS with cloud platform [14]. This paper will take the physics and electricity review class of junior high school as an example, carry out the research on the effect of deep learning implementation of physics review class based on CRS, and explore the influence of CRS teaching on the achievement degree of students' deep learning.

\section{Method}

\subsection{Design of the Study}

In this study, students from Class A and Class B of Grade 3 of Wuhan 19th Junior Middle School were selected as the research objects, and the review lesson of Chapter 16 "Voltage and Resistance" of Grade 9 in Physics of Junior Middle School published by PEP was selected as the case. Class A adopts the design mode of exercise sequence based on CRS, such as easy-hard-hard and rapid-fire, while Class B adopts the teaching mode of traditional review class. This study will qualitatively discuss the necessity and teaching efficiency of the application of CRS-based recitation lessons, and analyze the differences in teaching effects, students' attainment of deep learning and learning types [15].

\subsection{Conduct of Research}

Based on the CRS, this study constructs the deep learning mode [16] of physics review class in middle school, designs the physics classroom teaching flow according to the deep learning path, revolves around the core problems in the students' pre-evaluation, and realizes the training of students' higher order thinking through the solution of new problems. The teaching practice flow is divided into three links: preparation before class, deep processing in class and reflection after class as shown in figure 1 .

Before class, the students log on to the cloud platform to complete the pre-class test, the system synthetically analyzes the student data, and pushes it to the teacher in the form of visualization. Teachers grasp the core problems of students' cognition, prepare lessons pertinently, determine the important and difficult points of teaching, and design the corresponding teaching situation. Combined with cloud platform data, the teaching design portrays the students and locks the core problems to be solved in the classroom, and designs the corresponding $\mathrm{A} 、 \mathrm{~B} 、 \mathrm{C}$ three sets of test questions which accord with the scaffolding type. A series of scaffolding exercises (rapid-fire), based on scaffolding theory, helps students understand knowledge points step by step:

For example, around the use of voltmeters, teachers design a series of related problems to help students explore the rules of their role in different circuits, from the teacher's point of view of the difficulty balance, through the setting of topics to enable students to understand the knowledge points layer by layer.

Table 1. Discussion Questions and Results of "Voltage and Resistance".

\begin{tabular}{llll}
\hline Item & Core issues & Results & Need deep processing \\
\hline 1 & Voltage concept & $85 \%$ & \\
2 & Superconductivity and semiconductors & $100 \%$ & $\sqrt{ }$ \\
3 & Influencing factors of resistance & $88 \%$ & $76 \%$ \\
4 & Use of voltmeter & $65 \%$ & \\
5 & Use of sliding rheostat & $76 \%$ & $\sqrt{ }$ \\
6 & LED and integrated circuit & $74 \%$ & $\sqrt{ }$ \\
7 & Voltage law of parallel circuit & $53 \%$ & $24 \%$ \\
8 & Voltage law of series circuit & $65 \%$ & $85 \%$ \\
9 & Black box problem of ammeter and voltmeter & $85 \%$ & \\
10 & Circuit fault & & \\
11 & Judgment of positive and negative poles of power supply & \\
\hline
\end{tabular}

In class, teachers first lock in the core problems to be solved before class, and guide students to review the important knowledge points that need deep processing. And then the teacher shows the problem of the core problems to be solved in the class, and operates the CRS cloud platform classroom response system to detect the students' content in time. Students think independently within the specified time, submit answers on the handheld keyboard. The feedback of CRS in the first test results. Voltage and Resistance, is shown in Table 1. Based on CRS depth learning, the teaching mode of research learning, autonomous learning and peer learning is integrated in class. If the correct rate of the first test results is more than $70 \%$, as in question 1 , then ask the student to analyze the question and go to the next question. If the first test was $30 \%-70 \%$ correct, as in question 5 , students need to discuss with their classmates at the specified time in class. The teacher uses B set of test questions to design new situational problems to test the knowledge points that need to be deeply processed again. If the correct rate of the first test results was less than 30 percent, as in question 9, teachers guide students to review relevant knowledge points and analyze topics, and create new situational problems. The teacher uses the actual inquiry experiment to show the students' reasoning hypothesis in front of the students, to verify the students' physical concept 
by experiments, and to improve the students' interest in learning through experiments. According to the results of the second test, the teacher led the students to discuss the problems in the exercises again, use $\mathrm{C}$ set of test questions to test, and observe the answer to determine whether this knowledge needs to be summarized. Finally, the teacher summarizes the mistakes and difficulties of middle school students in class. After class, the teacher analyzes the students' classroom interaction, the correct rate of exercises and other learning data, determines the training questions after class, and adjusts the teaching arrangement of the next stage according to the overall situation of the class. Teachers push students' learning reports to their parents through the micro-school platform, parents can also log on to WeChat at any time to understand the general situation of students, students can also reflect according to the learning report.

From the results of the first test of "Voltage and Resistance ", it is found that the core problems that students need to solve in class are the use of sliding rheostat, the voltage law of series circuit, the black box problem of ammeter and voltmeter. When the correct rate of the first test results is less than $30 \%$, teachers should pay close attention to it, which indicates that most students have difficulties here.

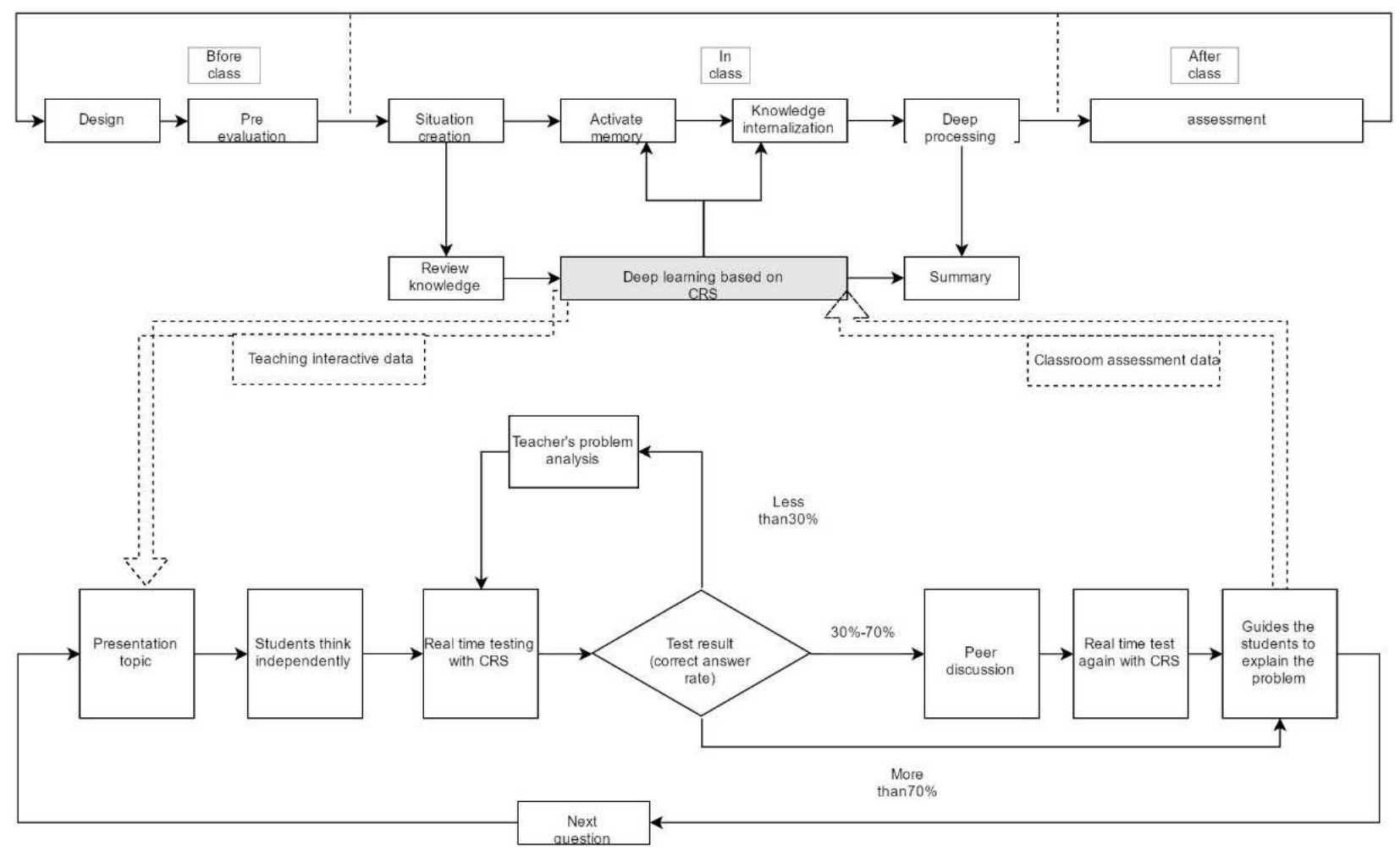

Figure 1. Based on the Deep Learning Model of Physics Review in CRS Middle School.

\subsection{Final Examination of the Same Knowledge Point}

In this study, the knowledge points of the core problems in the course are classified, the use of sliding rheostat, the voltage law of series circuit, the black box problem of ammeter and voltmeter, and the four knowledge points of circuit fault are selected for comparative analysis before and and after measurement. The difficulty of post-test is slightly higher than that of pre-test.

\section{Results}

\subsection{Efficiency of Physics Review in Junior High School Based on CRS Teaching}

Based on the characteristics of CRS interaction and timely feedback, teachers can directly judge the students' mastery of the core knowledge points corresponding to the subject by the test results in the classroom, so as to choose the appropriate learning mode. When the first test result is more than $70 \%$, most of the students have a good grasp of this knowledge can adopt autonomous learning model; When the results of the first test are between 30 and 70, some students do not have a deep understanding of the knowledge point, do not reach the goal of in-depth learning, can adopt the learning model of cooperation with each other; When the result of the first test is less than 30, most students have difficulties in this knowledge point. They can help students understand by means of teacher guidance and instruction, and teachers can create new situation problems for discussion and study in order to achieve the goal of deep learning. Compared with the traditional teaching mode of review class, the direction of review class based on CRS is clearer and more targeted, which improves the teaching efficiency of review class.

\subsection{Effect of Physics Review Course Teaching Based on CRS in Junior Middle School}

By CRS timely feedback data in class, we can understand 
the correct rate of students' answer questions in time, train the scaffolding exercises sequence, and correct the students' wrong physical concepts, which is helpful for students to master the core problems. The teaching effect of the core problems can be reflected by comparing the experimental class with the control class. The pre-test adopts the knowledge point test questions covering all the core problems before review, and the post-test sets up multiple choice questions corresponding to the four knowledge points. Pre-test and post-test were carried out in two classes, and the statistical data of pre-test and post-test results are shown in Table 2:

Table 2. Summary of statistical data of pre and post test results.

\begin{tabular}{llllll}
\hline Type of test & Class & N & Means & SD & \multicolumn{2}{c}{ P-value } \\
\hline \multirow{2}{*}{ Pretest } & A & 35 & 31.36 & 7.31 & 0.305 \\
\multirow{3}{*}{ Posttest } & B & 32 & 29.30 & 8.76 & 1.0305 \\
& A & 35 & 27.84 & 6.51 & 0.039 \\
\hline
\end{tabular}

The experimental class and the control class pre-test showed that the average value of the A class was slightly larger than that of the B class. The average score of the two classes was tested, and it was found that there was no significant difference in the original knowledge level between the two classes $(\mathrm{P}=0.305>0.05)$. The post-test of the two classes showed that the average of A classes (27.84), the average of B classes (23.31), the scores of students in the two classes were significantly different $(\mathrm{P}=0.039<0.05)$, and the fluctuation of students' scores in A classes decreased.

\subsection{CRS-based Refresher Courses Promote Students' Deep Learning}

Focusing on the core problems based on the CRS review class, the experimental inquiry is integrated into the situational problem solving created by the problem, which not only strengthens the students' interest in the exercise class, but also promotes the students' deep learning. To understand the degree of achievement of students' deep learning, the A class students were investigated by a deep learning questionnaire. The questionnaire was in the form of a Likert five-point scale, from "very disagree" to "very agree" with the A、B、C、D、E marking method. The statistical results are shown in Table 3.

According to the research data, the physics intelligence classroom based on the CRS model has a positive effect on the students' achievement in the experimental class. After classifying the types of study by shallow and deep, student's deep learning score is much higher than a shallow learning score (DA $>$ SA), deep learning motivation score greater than shallow learning motivation $(\mathrm{DM}>\mathrm{SM})$, about three times the proportion of students using deep learning strategies is about (DS $>$ SS), it shows that most students accept deep learning strategies, as shown in Table 4.

By comparing the experimental results, it can be found that the physics review class based on CRS can promote the achievement of students' deep learning goals, help to enhance students' deep learning motivation and strategies, and can also significantly improve students' grades and improve classroom efficiency.

\section{Conclusion}

By comparing the experimental results, it can be found that the physics review class based on CRS can promote the achievement of students' deep learning goals, help to enhance students' deep learning motivation and strategies, and can also significantly improve students' grades and improve classroom efficiency.

\subsection{CRS Make the Classroom More Alive}

By using the advantage of CRS timely feedback, teachers can grasp the students' learning situation in time, and guide the students to switch between different learning modes according to the correct rate of answering questions. By using the timely feedback of the CRS, teachers play their leading role and arrange the teaching rhythm more reasonably, and the classroom becomes a presupposition. By using CRS timely feedback, teachers can freely switch the appropriate teaching mode in class. Feedback each student's learning process through CRS data, paving a way from surface learning to deep learning. Even in face-to-face classes, students often feel isolated, lack motivation, and get used to passive receptive learning. Dynamic teaching mode switching makes students feel that they are an important part of classroom learning, their participation is valued by their peers, and their suggestions are encouraged by their peers. Students are constantly reviewed by their peers for feedback, which inspires each student to put their best efforts into the classroom, and at the same time, they constantly upgrade their physics learning strategies to meet the requirements of deep learning in the interaction.

\subsection{CRS Innovative Evaluation Methods}

Based on the CRS of junior high school physics review class effective feedback, positive interaction, instant evaluation and other characteristics and physics teaching links more in-depth integration, improve the efficiency of the classroom. At the same time, give full play to the ability of data analysis to focus on the core problems in the classroom, accurately locate the real teaching problems and carry out advanced training to achieve the goal of core literacy education. The advantage of data analysis innovates the evaluation method of learning process, affirms students' learning effect from participation rate, enthusiasm and correct rate, and improves students' sense of achievement and enthusiasm. Based on the CRS classroom, the main body of 
evaluation is expanded, students' evaluation of students, students' evaluation of themselves, teachers' evaluation of students, etc., so that students can understand themselves more comprehensively and objectively. Based on the CRS classroom to pay attention to the evaluation of the learning process, so that students' learning goals are more clear, learning attitude, classroom performance, homework quality, behavior habits and other aspects of progress, learning results naturally progress.

\section{Discussion}

Based on the CRS depth learning process model, the practical effect is ideal. Students' enthusiasm for learning is very high, and internal motivation is effectively stimulated. Students' ability of understanding and criticism, integration and construction, transfer and application, problem solving, evaluation and creation are all trained and promoted to different degrees, which effectively promotes the occurrence and maintenance of deep learning. However, the cultivation of students' deep learning consciousness and ability can not be realized in a short period of time in a class, a teacher and a new teaching mode. It needs the continuous improvement of teachers' professional accomplishment, the strong support of the school, and the benign guidance of the family and society. In the long run, the students' consciousness and ability of deep learning will be improved continuously, and can meet the requirements of lifelong learning ability in the information age. In the further study, we can explore more appropriate teaching mode in terms of teaching contents, methods and evaluation according to different teaching requirements of physical concepts and laws. Further optimization of CRS data analysis is more convenient for teachers to track the changes of each student before and after class, and to explore the implementation of teaching according to their aptitude and individualized learning, build a bridge for each student from surface learning to deep learning.

Table 3. Statistical results of questionnaire survey on deep learning effect of junior high school physics review course based on CRS.

\begin{tabular}{ll}
\hline $\begin{array}{l}\text { Partial problem } \\
\text { sequence }\end{array}$ & Problem description \\
\hline 1 & I will also spend my spare time in-depth understanding the interesting physics topics discussed in class. \\
2 & In the review, I will summarize the scattered physical knowledge. \\
3 & $\begin{array}{l}\text { I found that in the review class, the teacher combined with experiment or inquiry activities to carry out teaching is } \\
\text { helpful for my understanding. }\end{array}$ \\
4 & When I encounter some problems in my life, I will try to explain and solve them with physical knowledge. \\
4
\end{tabular}

Table 4. Analysis and comparison of learning types of junior high school physics review based on CRS.

\begin{tabular}{llll}
\hline \multirow{2}{*}{ Comparison project } & Deep Approach (DA) & Surface Approach (SA) \\
\cline { 2 - 4 } & Deep Motivation (DM) & Deep Strategy (DS) & Shallow Motivation (SM) \\
\hline Proportion of motivation and strategy & $57.6 \%$ & $75.5 \%$ & $42.4 \%$ \\
Proportion of learning types & $68.2 \%$ & & $31.8 \%$ \\
\hline
\end{tabular}

\section{References}

[1] Marton F, Saljo R (1976). On qualitative difference in learning: Outcome and process. British Journal of Educational Psychology, (1): 4-11.

[2] L. w. Anderson, et al; PI Liansheng Trans. Taxonomy of learning, teaching and evaluation: revised version of Bloom's taxonomy of educational goals. East China Normal University, Shanghai, 2008; pp. 28.

[3] An Fuhai (2014). Research on classroom teaching strategies to promote deep learning. Curriculum, teaching materials and teaching methods, (11): 57-62.

[4] Li Gang, Zhang Xiaowei, Hou Shu (2015). Investigation and practical classification of middle school physics teaching methods. Teaching and management, (18): 108-110.

[5] Eric Mazur (2009). Farewell, Lecture?. Science. 2: 50-51.

[6] Chen Zhenzhen (2013). Designing and Instructing CRS-based College English Courses_-A Case Study Using Socrative. Modern Educational Technology, 23 (10): 87-91.

[7] Ryan Sayer, Emily Marshman, and Chandralekha SinghPhys
(2016). Case study evaluating Just-In-Time Teaching and Peer Instruction using clickers in a quantum mechanics course. Rev. Phys. Educ. Res. 12, 020133.

[8] He Miaoman, Huang Zhixin and Zhou Dongying (2017). The preliminary study of seminar in college physics class based on cliker. Physics and Engineering, 27 (03): 45-51.

[9] Neville W. Reay, Lei Bao, Peng fei Li (2005). Toward the effective use of voting machines in physics lectures. Am. J. Phys, 73 (6): 554-558.

[10] Kelly Miller, Julie Schell, Andrew Ho, Brian Lukoff, and Eric Mazur (2015). Response switching and self-efficacy in Peer Instruction classrooms. Phys. Rev. ST Phys. Educ. Res. 11, 010104.

[11] Risto Leinonen, Mervi A. Asikainen, and Pekka E. Hirvonen (2017). Peer discussions in lecture-based tutorials in introductory physics. Phys. Rev. Phys. Educ. Res. 13, 010114.

[12] M. K. Smith. Why peer discussion improves student performance on in-class concept questions. Science. 2009 (2): 122-124.

[13] Huang Zhixin (2010). Interactive and inquiry classroom teaching based on clicker and its research progress. Discussion on physics teaching, 28 (09): 1-4. 
[14] Yu Jie Chen, Mi Su, Zhi Xin Huang (2020) Review Seminar Based on CRS in Introductory Physics. Science Journal of Education. 8 (4): 108-113.

[15] Li Yubin, Su Danrui, Li Qiuyu, Ren Yonggong (2018) Development of College Students' deep learning scale for mixed learning environment. Research on audio visual education. 39 (12): 94-101.

[16] Eric Jensen; LeAnn nickelsen; Warmth, Trans. Seven powerful strategies for deep learning. East China Normal University, Shanghai, 2009; pp. 11-12. 